adequate for numbers of any size likely to be encountered. But of perhaps even greater value is the reference to an hypothesis which seems startling when encountered as early as the third century $\mathrm{BC}-$ namely, that the sun, not the earth, is at the center of our universe. We regret deeply that Archimedes, a younger contemporary of Aristarchus, did not tell us more about this hypothesis. The only book of Aristarchus which has been preserved is a treatise: On the dimensions and distances of the sun and the moon. This contains no mention of any hypothesis on the planetary system. However, two brief refercnces by other writers include the hypothesis, including, in the case of a reference by Plutarch, the inclusion of the rotation of the earth on its axis.

As is frequently the case, a study of work in one field yields, almost as a side issue, material of equal if not greater importance in a related field.

\title{
EUROPEAN TRAVEL STUDY PROGRAM IN COMPARATIVE EDUCATION
}

Wayne State University's College of Education and Graduate Division again approve credit arrangements in connection with the 14th Annual European Travel Study Program in Comparative Eeucation. Personally directed by Dr. Wm. Reitz, Professor of Education, the group will leave Detroit on June 24 and return on September 1, 1961.

Visiting 13 countries during the 10 weeks' journey, this program is designed to provide teachers, students, and other professional people with opportunities to survey selected highlights of the life and culture of Western Europe. There are approximately 425 alumni of past programs.

Persons may qualify to earn from 2 to 6 hours of graduate or undergraduate credit - to apply on degree programs, for teaching certification, or for annual salary increments. Others may register for "audit" credit and participate in the program for purposes of personal or professional enrichment.

Arrangements will be offered on two price levels: (1) regular first class program; and (2) economy program. All-inclusive land and cruise costs for the first class program are about $\$ 1535$ and, for the economy program (without cruise), \$940-plus in either class, the Trans-Atlantic roundtrip air fare.

Special highlights of the 1961 program include an Adriatic and Aegean cruise visiting ports of Greece and Turkey: Corfu, Athens, Mykonos, Delos, Istanbul, Bosphorus, Troy, Rhodes, Crete, Delphi, Nauplia, and Brindisi.

Further information may be obtained from Dr. Wm. Reitz, College of Education, Wayne State University, Detroit, 2, Michigan.

The University of Michigan has received word from the National Science Foundation that an Academic Year Institute will be supported for high school teachers of chemistry, mathematics, and physics during the year 1961-62. Information regarding the Institute can be obtained from

Professor L. C. Anderson, Director

1018 Angell Hall

The University of Michigan

Ann Arbor, Michigan 